$$
\begin{aligned}
& \text { ACORDO DE PES } \\
& \text { COMO GESTÃO } \\
& \text { RECURSOS: O C } \\
& \text { DA ILHA DE SÃO MIG } \\
& \text { SANTAREM, P. }
\end{aligned}
$$




\section{ACORDO DE PESCA COMO GESTÃO DOS RECURSOS: O CASO DA ILHA DE SÃO MIGUEL, SANTARÉM, PARÁ}

ROBERTH RODRIGUES FERREIRA ${ }^{1}$

UNIVERSIDADE FEDERAL dO OESTE DO PARÁ

RUBENS ELIAS DA SILA²

UNIVERSIDADE FEDERAL DO OESTE DO PARÁ 


\section{ACORDO DE PESCA COMO GESTÃO DOS RECURSOS: O CASO DA ILHA DE SÃO MIGUEL, SANTARÉM, PARÁ}

\section{Resumo}

Este artigo tem como objetivo compreender a construção e consolidação do acordo de pesca de base comunitária como uma alternativa viável de gestão dos recursos pesqueiros na comunidade Ilha de São Miguel localizada na região de várzea do rio Amazonas no município de Santarém, Estado do Pará. A atividade pesqueira nesta localidade transformou socialmente de modo que produção econômica da pesca passou do status de subsistência à pesca comercial de caráter exploratório levando ao exaurimento de algumas espécies de pescado nos lagos locais. Como consequências disto, os comunitários da Ilha se engajaram ações que visam a preservação e manutenção dos recursos pesqueiros, bem como seus territórios extrativos. Essas ações foram elaboradas em um acordo para preservação dos recursos do lago através da suspensão do uso de malhadeiras na comunidade. Contudo, esta decisão criou conflitos entre os membros da comunidade e pescadores das comunidades circunvizinhas levando o grupo local a criar um acordo de pesca no ano de 1985 o qual restringiu a pesca na Ilha apenas aos seus moradores, bem como a proibição definitiva do uso de malhadeiras. Este acordo é mantido até os dias atuais, que juntamente com outras estratégias consolidadas pelos moradores, tais como o manejo e controle da comercialização do pirarucu (Arapaima gigas) e fiscalização dos lagos pelos pescadores, evidenciando uma alternativa promissora para uma gestão da pesca por meio do uso racional dos recursos pesqueiros na comunidade.

Palavras-chave: Acordo de pesca, gestão de recursos pesqueiros, comunidade ribeirinha. 
FISHING AGREEMENT AS RESOURCES MANAGEMENT: THE CASE OF SÃO MIGUEL ISLAND, SANTARÉM, PARÁ

\begin{abstract}
This manuscript aims to understand the construction and consolidation of the community-based fishing agreement as a viable alternative for the management of fishery resources in the community of São Miguel Island located in the floodplain region of Amazon River in Santarém city, Pará State. Fishing activity in this locality has been socially transformed so that economic production of fishing has shifted from subsistence status to commercial fishing of exploratory character, leading to the depletion of some species in local lakes. Consequently, the community members of the Island have engaged in actions aimed at the preservation and maintenance of the fishing resources, as well as its extractive territories. These actions were elaborated in an agreement in order to preserve the lake resources by suspending the use of fishing nets in the community. However, this decision created conflicts between community members and fishermen from surrounding communities, leading the local group to create a fishing agreement in 1985 which restricted fishing on the Island to its residents only, as well as a definitive ban on the use of fishing nets. This agreement is maintained until the present day, jointly with other strategies consolidated by the residents, such as the management and control of the commercialization of pirarucu (Arapaima gigas) and inspection of lakes by fishermen, showing a promising alternative for a fishing management through the rational use of resources in the community.
\end{abstract}

Keywords: Fishing agreement, management of fishery resources, riverine community. 


\section{EL ACUERDO DE PESCA COMO GESTIÓN DE LOS RECURSOS: EL CASO DE LA ISLA DE SAN MIGUEL, SANTARÉM, PARÁ}

\section{Resumen}

Este artículo tiene como objetivo comprender la construcción y la consolidación del acuerdo de pesca de base comunitaria como una alternativa viable de la gestión de los recursos pesqueros en la comunidad de la Isla de San Miguel, localizada en la región de la várzea del río Amazonas en el municipio de Santarém, Estado de Pará. La actividad pesquera en esta localidad transformó socialmente el modo de producción económica, que pasó del estatus de subsistencia al de pesca comercial de carácter de explotación, lo que llevó al agotamiento de algunas especies de peces de los lagos locales. Como consecuencia, los comunitarios de la Isla se vincularon a acciones para la preservación y el mantenimiento de los recursos pesqueros, así como de sus territorios extractivos. Esas acciones fueron elaboradas en un acuerdo para la preservación de los recursos del lago a través de la suspensión del uso de redes. Con todo, esta decisión creó conflictos entre los miembros de la comunidad y los pescadores de las comunidades aledañas, que llevaron al grupo local a crear un acuerdo de pesca en 1985, el cual restringió la pesca en la Isla apenas a sus habitantes, y prohibió definitivamente del uso de redes. Este acuerdo, que se mantiene vigente, junto a otras estrategias consolidadas por los habitantes, como el manejo o control de la comercialización de pirarucu (Arapaima gigas) y la fiscalización de lagos por los pescadores, evidencian alternativas promisorias para una gestión de la pesca por medio del uso racional de los recursos pesqueros en la comunidad.

Palabras clave: Acuerdo de pesca, gestión de recursos pesqueros, comunidad riberiña.

Roberth Rodrigues Ferreira ${ }^{1}$

roberthrodrigues23@hotmail.com

Rubens Elias da Silva ${ }^{2}$

hellazer09@gmail.com 
Dedico ao meu pai, Luiz Vinhote Ferreira (Seu Lulu), pela sua constante luta pelos pescadores.

\section{INTRODUÇÃO}

Este artigo busca compreender a gestão dos recursos pesqueiros por meio de acordo de pesca de base comunitária na Ilha de São Miguel, comunidade de várzea do rio Amazonas, localizada no Município de Santarém, oeste do Estado do Pará. Entende-se por gestão dos recursos pesqueiros de pequena escala a estratégia de preservar estoques de animais em determinado ecossistema e sua interrelação com os atores sociais diretamente envolvidos no processo de captura de pescado dentro de patamares adequados à conservação de espécies (Berkes et al. 2008). Trata-se de uma importante ferramenta para controlar o acesso irregular e a consequente degradação do recurso (Oviedo et al. 2015). O texto busca, ainda, analisar as ações e estratégias criadas e estabelecidas para defender não somente o seu espaço, mas o modo de atuação e utilização dos recursos presentes, as formas de organização e uso dos territórios extrativos da pesca na várzea permitindo um entendimento da gestão da pesca no decorrer do ano nesse espaço natural.

A pesca na região amazônica é uma prática produtiva em que boa parte da população se mobiliza, direta ou indiretamente, na captura, venda e consumo familiar (Smith 1979, Furtado, 1997), fato amplamente reconhecido na literatura (Lathrap 1968, Meggers, 1971). Vale frisar que grande parte da população no território amazônico brasileiro está concentrada ao longo dos rios, a fim de desfrutar das proteínas da fauna aquática, do transporte fluvial e do uso de terras férteis para o plantio (Smith 1979). Estudos referentes à pesca no espaço amazônico atestam que ela é anterior a colonização do território brasileiro (Veríssimo 1970). Esta atividade passou por um processo de evolução marcado por inovação tecnológica e pela captura mais eficiente para fins de lucratividade, comandado pela pesca comercial. Em meio a esse processo, as comunidades amazônicas de várzea entendem a pesca como atividade de exploração de recursos locais cuja capacidade de exaustão dos recursos pesqueiros é pequena, o que explica a pequena acumulação de renda - conhecida como pesca de subsistência (Santos \& Santos 2005). Segundo alguns autores, como Diegues (1983), esta referência a diferentes grupos sociais de pescadores tem estreita relação com o campesinato, pois a captura do pescado está intimamente relacionada à produção de outros artigos, como feijão, mandioca, leguminosas, pequenas aves e frutos.

Ao estudar as experiências recentes de gestão participativa da pesca na Amazônia, Oviedo et al (2015) aponta que a intensidade expletiva dessa atividade nas várzeas amazônicas toma duas direções distintas: uma, relacionada à sustentabilidade dos recursos, preocupação latente nas comunidades varzeanas que lidam sempre com o espectro da possível perda dos recursos pesqueiros; outra que se expressa nos interesses de forasteiros que têm 
acesso ao recurso, explorando-o indiscriminadamente e, cujo impacto no ambiente é superlativizado pela tecnologia adotada e pela busca por lucro. Nesse contexto de conflito entre diferentes atores sociais com intencionalidades distintas com relação ao acesso e uso dos recursos pesqueiros locais na Amazônia, a gestão comunitária dos recursos é chamada de "acordo de pesca”. O acordo é uma importante ferramenta para controlar o acesso irregular e a consequente degradação dos recursos pesqueiros (Oviedo et al. 2015). Pelo acordo, a responsável pelo monitoramento dos territórios de manejo do pirarucu na Ilha de São Miguel é a Associação dos Nativos e Moradores da Ilha de São Miguel - ANMISM ${ }^{3}$.

A pesca de águas interiores responde por mais de $50 \%$ da produção pesqueira estadual no Pará. Em termos socioeconômicos, possui características específicas como modalidade produtiva basicamente artesanal, cuja produção abastece mercados locais, fornecendo sustentação alimentar e de renda em áreas pouco desenvolvidas (Hartmann 2001). No entanto, o aproveitamento indiscriminado dos recursos pesqueiros levou a competição entre grupos de pescadores e comunidades no interior de lagos e rios na região, agravado pelo surgimento de novos atores como o de pescadores profissionais embarcados vindos de outros centros regionais de produção e distribuição do pescado, como Manaus e Belém. Somando-se a isso, o uso indiscriminado de apetrechos inadequados gerou conflitos entre grupos de pescadores e comunidades ribeirinhas, além da dis- puta entre aqueles atores e outros setores econômicos - barcos motorizados com alto poder de exploração do pescado e suas relações com mercado em centros regionais - para aproveitamento das margens de rios e lagos, várzea e terra firme; por fim, a crescente poluição e outras transformações químicas e físicas dos recursos hídricos fizeram desaparecer espécies de pescado, desestruturando a cadeia produtiva de inúmeras comunidades ribeirinhas (Hartmann 2001).

Estudos apontam intensas rivalidades entre pescadores locais e embarcações vindas de outras regiões do Pará e Amazonas para capturar pescados no oeste paraense, como em Aramanaí (Silva \& Salgado 2016), e a busca de regramento do acesso e usufruto de recursos, como no lago do Tapará (Lima 2014). Essas dinâmicas sociais ocorridas no interior da Amazônia e, em especial, no oeste paraense, despertaram a necessidade de diversas comunidades ribeirinhas e lacustres a mobilizarem-se politicamente no sentido de elaborarem estratégias de administrar os recursos bióticos de lagos e rios, o que levou aos acordos de pesca. Esta condição implantada na região criou um aumento na exploração do recurso pesqueiro e agravamento dos conflitos sociais por divergência de interesses (pesca de subsistência versus pesca comercial), fazendo os moradores, a partir da década de 1970, criarem estratégias de defesa de seus espaços de uso comum (os pontos de pesca), por meio dos acordos de pesca comunitários (Azevedo \& Apel 2004, 
Mcgratt et al. 1993, Batista et al. 2004, Ximines 2008) tendo por objetivo defender a necessidade de preservação das espécies de pescado bem como ser reconhecido e respeitado por outros grupos de pescadores. Entre as diversas mudanças ocorridas na atividade da pesca na Amazônia, destaca-se, a partir da década de 1960, a criação da Superintendência do Desenvolvimento da Pesca - SUDEPE - por iniciativa do Estado, a qual tinha por objetivo implantar o Plano Nacional de Desenvolvimento da Pesca - PNDP - e impulsionar um aumento na produção de recursos pesqueiros por meio dos incentivos fiscais, que forneciam auxílios técnicos e financeiro ao setor pesqueiro na região amazônica por meio de incorporação de novas tecnologias de captura de pescado (Ruffino 2005), o plano não levava em consideração o desenvolvimento das comunidades ribeirinhas que tinham a pesca como principal fonte de dieta alimentar e renda (Melo 1993, Mcgratt et al. 1993, Batista et al. 2004, Cerdeira 2009).

Diante disso optou-se por estudar a comunidade Ilha de São Miguel, localizada nas proximidades da margem esquerda do Rio Amazonas no espaço da várzea da microrregião do Aritapera, no município de Santarém, mesorregião do Baixo Amazonas, no Estado do Pará. Ademais, essa comunidade possui um acordo de pesca comunitário construído em 1974, consolidado no ano de 1985 e em vigor até os dias atuais, permitindo analisar o acordo de pesca como uma alternativa de gestão dos recursos pesqueiros.
O texto busca responder três indagações, a saber: (i) Qual fator fez a comunidade criar um acordo de pesca visando a preservação dos recursos pesqueiros? (ii) Como a comunidade passou pela modificação da prática da pesca a partir das regras do acordo? (iii) Quais as estratégias atuais adotadas pela comunidade para preservar os recursos pesqueiros?

Com relação ao aporte metodológico, foram aplicadas entrevistas semiestruturadas com quatro moradores da Ilha de São Miguel e uma com um ex-morador, atualmente representante do Movimento dos Pescadores e Pescadores Artesanais do Oeste do Pará e Baixo Amazonas (MOPEBAM) que compreendem a faixa etária entre 32 a 74 anos. Como nossa abordagem antropológica está centrada na história de vida (Bosi 2003) a partir das memórias socialmente partilhadas (Halbwachs 2006) dos ilhéus de São Miguel, o estudo aprofundado das subjetividades dos cincos atores sociais faz-se oportuna e metodologicamente possível. As entrevistas foram norteadas tomando como base o diálogo, no sentido de construir laços de confiança entre pesquisador e interlocutores.

A pesquisa teve como foco os atores envolvidos na construção deste modelo de gestão participativa dos recursos pesqueiros. Foram registradas as histórias envolvendo a atividade produtiva da pesca como base alimentar, fonte principal de renda, a crise dos recursos pesqueiros, a implantação e consolidação do acordo de pesca e a atividade da pesca na atualidade. 
O LUGAR DA PESQUISA DE CAMPO

A comunidade dista aproximadamente $56,79 \mathrm{~km}$ da sede do município, a cidade de Santarém. Possui uma escola de Ensino Fundamental, onde também funciona o Ensino Médio Modular; para os momentos de lazer e acolhimento espiritual, os comunitários têm um clube de futebol e duas igrejas, uma católica e outra de matriz evangélica. $\mathrm{O}$ acesso à cidade dá-se exclusivamente por via fluvial. Para isso, os comunitários utilizam pequenas embarcações, motorizadas, chamadas bajaras, ou embarcação de porte médio, chamada "barco de linha", que transportam os moradores e seus produtos extrativos e agrícolas da comunidade até Santarém. As viagens de barco de linha a Santarém acontecem três vezes por semana perfazendo o percurso comunidade sede do município em aproximadamente 4 horas.

Figura 1 - Mapa de localização da comunidade Ilha de São Miguel, Santarém, Pará

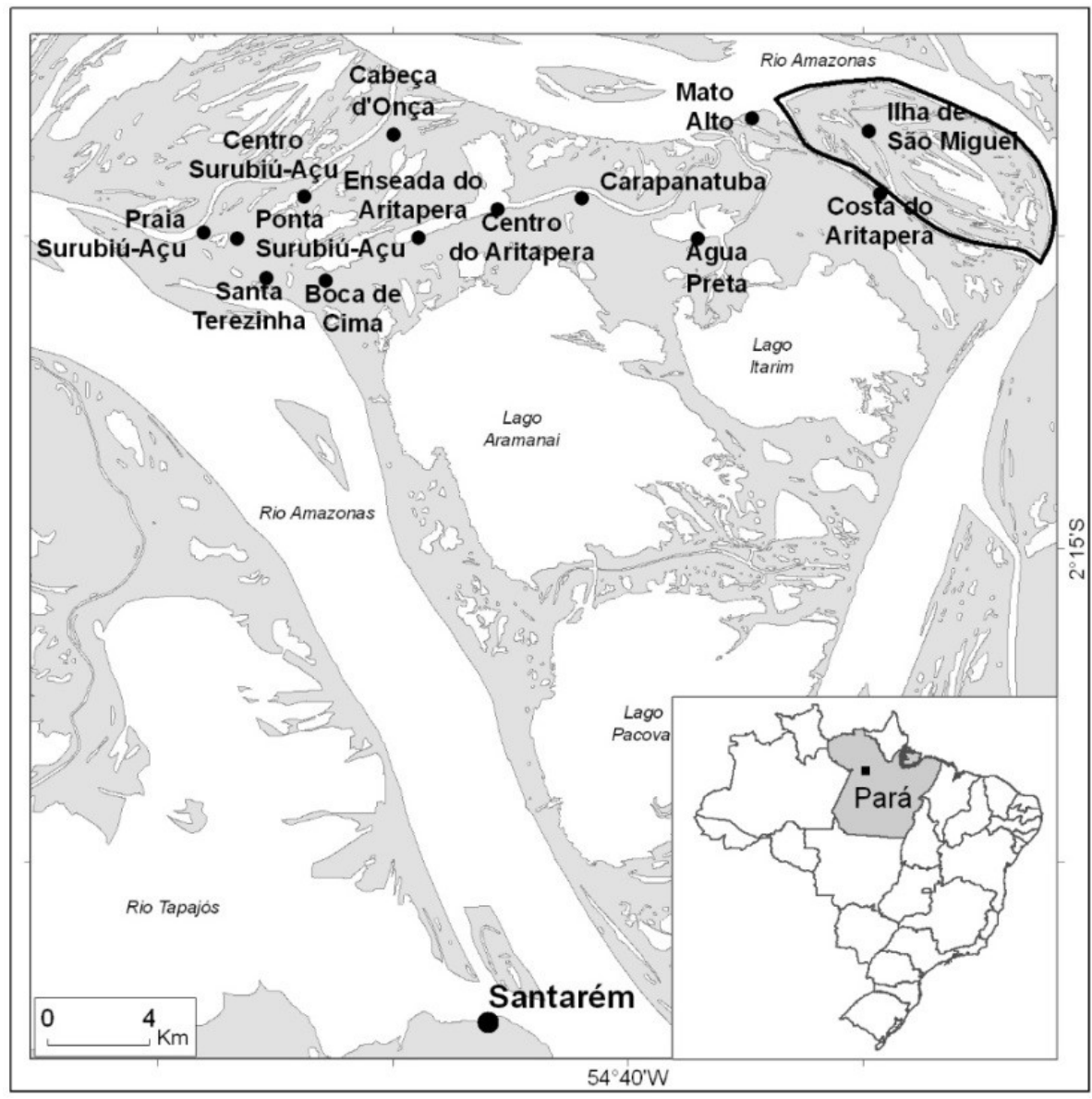

Fonte: Instituto de Pesquisa Ambiental da Amazônia (IPAM), 2011. 
Por situar-se na várzea, essa comunidade possui um modo de vida adaptado ao regime hídrico dos rios da região em um processo de subida e descida dos níveis da água, no decorrer no ano, onde seus trabalhos produtivos necessariamente obedecem à época que cada atividade deve ser desenvolvida. Possuindo, atualmente 46 famílias, que usam e controlam o território da comunidade de aproximadamente 3.500 hectares. A coletividade apresenta uma cotidianidade, centrada na atividade pesqueira, mantida por todos ali presentes mirando à preservação das espécies, a partir de uma relação íntima com a natureza e com as mudanças ocorridas neste espaço.

Figura 2 - Ilha de São Miguel.

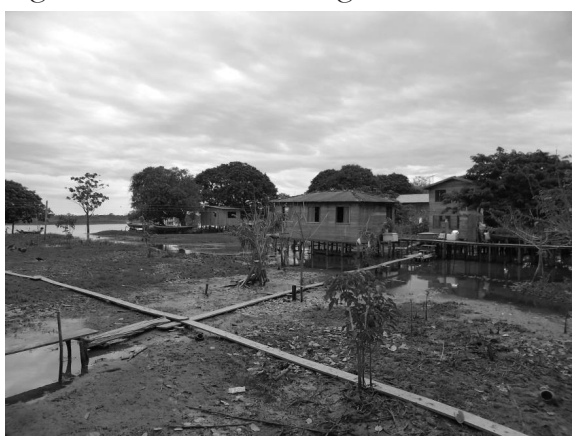

Fonte: Roberth Rodrigues Ferreira (2017).

A pesca enquanto atividade produtiva sempre esteve presente no cotidiano da comunidade Ilha de São Miguel. A utilização desse recurso tinha/tem como prioridade o sustento das famílias ali residentes, sendo o excedente da produção diária vendido para garantir a compra de outros materiais necessários à existência do grupo.
Figura 3 - As habitações na ilha de São Miguel são construídas com recursos madeireiros e apropriadas para enfrentar períodos de cheia e seca.

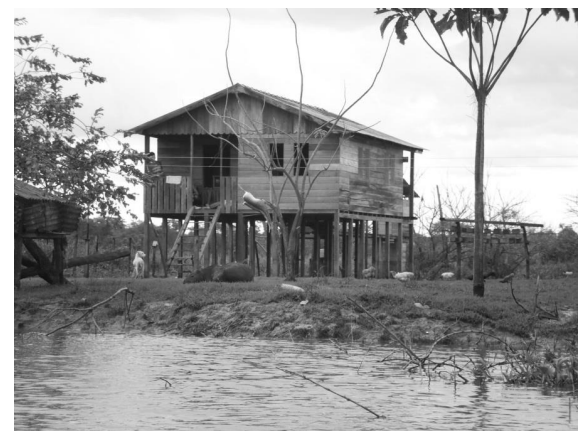

Fonte: Roberth Rodrigues Ferreira (2017).

Ademais, ressalta-se que, em um passado recente, houve nesta localidade exploração desordenada dos recursos pesqueiros feita pelos pescadores locais e das comunidades circunvizinhas, trazendo grandes prejuízos aos moradores, os quais buscam a partir do acordo de pesca na tentativa de direcionar a relação homem/natureza, conservando não somente os recursos, mas também sua identidade de vida tradicional.

\section{A PESCA EM SÃO MIGUEL: DA FAR- TURA À FALTA DO PEIXE}

A comunidade tinha até meados da década de 60 uma vida centrada em uma produção e utilização da variedade dos recursos locais. Nos relatos dos moradores, a produção da coletividade se baseava na juta, criação de gado, plantação de roça e roçado e a pesca. Até então a pesca fora uma atividade utilizada somente para subsistência.

"A Ilha de São Miguel era uma comunidade muito populosa né, tinha 
bastante gente naquele período né? E, só que a sobrevivência da pesca era muito pouca, a maior parte trabalhava na agricultura né? A juta era uma produção do auge naquele tempo, era da onde se ganhava dinheiro era da produção da juta, e, a população que trabalhava na juta ela não pescava a não ser só pra sua alimentação, pra subsistência" (Entrevistado 01).

O relato desse interlocutor indica que a atividade geradora de renda na comunidade era o cultivo da juta. A pesca de subsistência gerava uma reduzida demanda dos recursos pesqueiros. Devido ao declínio do cultivo da juta na região na década de 1970, essa atividade tornou-se inviável na promoção e garantia de renda local. O grande estoque pesqueiro e a variedade de espécies presentes nos lagos da comunidade foram determinantes nas mudanças sociais ocorridas na atividade econômica da Ilha de São Miguel, tornando a pesca lacustre o principal meio de obtenção e geração de renda e mais, objeto que passou a ser fruto de intenso debate sobre como pescar, quando pescar e quais atores sociais podem participar da atividade em termos locais.

Figura 4 - Lago próximo à Ilha de São Miguel.

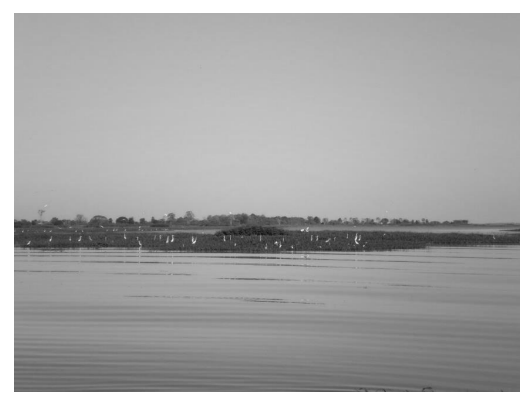

Fonte: Roberth Rodrigues Ferreira (2017).
Dessa forma, os moradores da Ilha buscam na atividade da pesca encontrar soluções para garantir a existência e perenidade do grupo. Não obstante, a escolha dessa atividade se faz por alguns motivos que merecem ser destacados: a pesca é uma atividade destinada ao sustento familiar; o pescado é parte indispensável na dieta alimentar dos ribeirinhos; existe rica variedade no estoque pesqueiro nos lagos da comunidade; a pesca permite a geração de renda, mesmo que pequena, que por sua vez permite acesso a outros produtos localmente indisponíveis; existe a possibilidade do acesso dos pescadores a novas técnicas de captura do pescado, possibilitando aumento considerável na produtividade do trabalho e uma momentânea segurança para a reprodução do grupo familiar.

Segundo Ruffino (2005), a introdução das novas técnicas de captura do pescado surgiu a partir da criação da Superintendência do Desenvolvimento da Pesca (SUDEPE) a qual dava incentivos a pesca, por meio de diversos instrumentos tecnológicos, os quais aumentavam o poder de captura dos pescadores e consequentemente uma maior pressão sobre o pescado.

"Na mesma época, no interior da Amazônia, a introdução dos motores a diesel e das fibras de náilon monofilamento para as redes de emalhar, assim como a instalação de frigoríficos, deram o suporte técnico que faltava para uma mudança qualitativa no poder de pesca” (RUFFINO, 2005, p. 17).

Vê-se que as mudanças no setor pesqueiro destacadas pelo autor, prove- 
niente dos incentivos fiscais, fizeram a atividade pesqueira na região amazônica ganhar novas proporções, aumentando o número de pescadores/ empresários para a exploração/produção do pescado, causando com isso uma rápida diminuição do estoque pesqueiro na região (Maybury-Lewis 1997, Ruffino 2005). As mudanças do setor pesqueiro e as consequências destas na região amazônica são comentadas por ex-morador da Ilha, quando destaca:

"A partir que começou surgir a perca da atividade da juta, o comércio da juta, ai todo aqueles que trabalhavam na juta passaram a ser pescador. Eis que coincidiu na década final de sessenta e início de setenta com a implantação da SUDEPE na região, que era a Superintendência do Desenvolvimento da Pesca, e ela trouxe um desenvolvimento da pesca, mas não pra organizar os pescadores ou os comunitários, mas pra trazer uma nova tecnologia de como pegar peixe, como pescar, foi então que chegou as malhadeiras, né? Essa tomada de decisão, ela chegou a trazer o que? Que os nossos lagos os nossos rios não tavam preparado pra receber essa forma de pesca em grande escala né? E o que aconteceu? Que aconteceu que foi um grande prejuízo nas populações das espécies que tavam dentro dos lagos né. (Entrevistado 02 e ex-morador da comunidade)".

Segundo o entrevistado, a realização dessa atividade, de forma intensificada e predatória, trouxe em um curto período escassez dos recursos pesqueiros na região. Tal atitude acarretou, em curto período, a falta do pescado às mesas dos comunitários.
"Bem, quando foi mais ou menos em 70, entrou um pessoal do Urucurituba aqui, meteu motor pro lago e começaram a botar malhadeira, nós não usávamos malhadeira na época, nessa época não, e começaram a dar "pau em peixe". Atrás deles veio o pessoal do Arapemã, veio o pessoal do Saracura, aí dessa região de Barreira, Correio, Costa do Aritapera, aí eu ainda disse pro pessoal: olha vão acabar o peixe da Ilha porque eu vou lhe falar é o arreio mais prejudicial que existe no nosso meio é a malhadeira e lanterna de carbureto, esses dois. Bem eu comprei um motor e coloquei no lago e só vinha em casa trazer algum peixinho pra mulher $\mathrm{e}$ voltava, certo que praticamente zerou a parte de tambaqui, pirarucu, acari, esses peixes né? A gente não via praticamente nada já não tinha quase nem pra comer, (Entrevistado 03)".

A pressão sobre o pescado nos lagos da comunidade, feita pelos próprios moradores e das comunidades circunvizinhas, fez com que os recursos pesqueiros chegassem próximo ao escasseamento, segundo relatos de moradores locais. Tais atitudes vividas na prática cotidiana dos moradores da Ilha, parecem atestar o centro do debate de Hardin (1968), em sua teoria "a tragédia dos 'bens' comuns". Hardin afirma ser a racionalidade e ação individualista os principais elementos a acarretar prejuízos coletivos. No decorrer de alguns anos, essas práticas de captura do pescado em base predatória acarretaram prejuízos trazendo graves problemas à população da Ilha, principalmente com relação à alimentação 
e sustento das famílias. Veja como se refere este interlocutor:

"A Ilha de São Miguel foi uma comunidade que sofreu muito com isso. Sofreu um impacto muito grande no setor da pesca. Já tinha dificuldade que tinha família que quando almoçava não jantava né? E o peixe era de uma qualidade muito inferior do que se tinha a cinco dez anos atrás. Então virou a ser? só peixinho né? E não tinha condições de dar uma alimentação adequada aí a população começou a sofrer com algumas enfermidades e outras coisas que vinham aí por falta de uma alimentação adequada" (Entrevistado 02 e ex-morador da comunidade).

Entende-se que o uso indiscriminado dos recursos pesqueiros no espaço da comunidade provocou a tragédia dos comuns referendada nos estudos de Hardin, pois o uso intensivo dos recursos, na busca por lucros individuais, ocasionou no período da fomitura na comunidade, criando instabilidade na obtenção de proteínas no cotidiano dos ilhéus. Esta instabilidade na vida social do grupo obrigou-o a determinadas tomadas de decisões e ações políticas sobre o uso do espaço na comunidade buscando equilibrar as demandas dos grupos familiares com os recursos pesqueiros disponíveis. É neste contexto que um conjunto de ações políticas locais, pensado pelos moradores, busca, por meio do uso racional e coletivo dos recursos comuns, criar e instituir normas e regras de uso dos recursos pesqueiros nos lagos da comunidade por meio de um acordo de pesca comunitário.

\section{A CONSTRUÇÃO DO ACORDO DE PESCA}

$\mathrm{Na}$ tentativa de recuperar o estoque pesqueiro, os comunitários da Ilha de São Miguel construíram estratégias que limitaram ou proibiram o uso e exploração do recurso pesqueiro nos espaços de pesca da comunidade. Essas estratégias se transformaram em acordo de usufruto no ano de 1974, posteriormente, em um acordo de pesca firmado entre os moradores no ano de 1983, sendo este homologado no ano de 1985. A criação de regras e estratégias políticas, para o uso dos recursos pesqueiros na comunidade Ilha de São Miguel, vai ao encontro da teoria proposta por Ostrom (2011), pois a co-gestão coletiva na comunidade e a comunicação existente entre os integrantes do grupo originaram uma relação de equidade com o meio proporcionando benefícios de usufruto para o grupo em vez do colapso vivido pelo mesmo anos atrás. Estas decisões políticas dão-se, principalmente, em relação às técnicas de capturas fazendo uso de apetrechos (malhadeira, tarrafa, lanterna e bomba de carbureto) que fazem o "peixe fugir" de determinados pontos de extração. Assim se refere um morador da Ilha sobre o uso destes instrumentos técnicos:

"Aí eu disse: se o pessoal concordasse nós íamos suspender a malhadeira, nós ainda temos condição de recuperar o lago. Embora com sacrifício, mas eu acredito porque ainda tem muitas partes de mazona, de lagos aí vizinhos que capaz que ainda tenha um peixe que possa chegar pra cá e produzir e aumen- 
tar. Aí eu convidei o pessoal e disse tudo o que era pra fazer, disse: olha gente, nós vamos fazer isso, vamos suspender e vamos ver como é que se comporta durante uns meses aí a parte do lago. Se der lucro aí nos continua, aí vai ser a decisão (Entrevistado 03)".

A posição política do entrevistado e sua tomada de decisão de reunir a coletividade da Ilha de São Miguel gera uma comunicação entre os membros da localidade. A existência de comunicação tira os comunitários do dilema do prisioneiro, na teoria dos jogos mencionado por Ostrom (2011), pois a partir da reunião, comentada pelo nosso interlocutor, iniciou uma ação coletiva no espaço da comunidade fundamentado no interesse coletivo e na busca do bem comum. Desta maneira, identificam-se traços de um acordo de usufruto, o qual trouxe como primeiro ato a suspensão do uso de malhadeiras nos lagos da comunidade, em um período de seis meses, objetivando retornar o estoque antes da pesca predatória, realizada por alguns pescadores da comunidade e das comunidades circunvizinhas.

Figura 5 - As decisões políticas locais dão-se em relação à restrição técnicas de capturas fazendo uso de apetrechos que fazem o "peixe fugir" de determinados pontos de extração. Na imagem, pesca de tarrafa no lago.

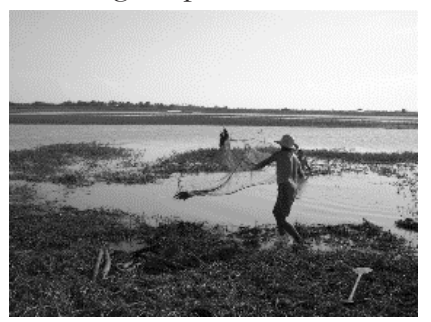

Fonte: Roberth Rodrigues Ferreira (2017).
$\mathrm{Na}$ visão dos comunitários, o uso intensivo da malhadeira reduziu os estoques pesqueiros, pois este apetrecho é o maior "vilão" e prejudica os locais das pescarias devido grandes volumes capturados sem seleção de espécies nem tão pouco tamanho do peixe capturado.

"Nós comecemos pescar de malhadeira. Aí nós vimo que o peixe tava se acabando, ficando velhaco os peixes. Aí nós reunimo, a comunidade reuniu e foi quando surgiu esse acordo que tá dando resultado, tá dando certo (Entrevistado 04).

Este acordo obteve um resultado positivo, no período de vigência, em função do aumento da quantidade e da diversidade das espécies de pescado em um curto período de tempo. A comunidade via que este seria o caminho para a conservação das espécies como o pirarucu (Arapaima gigas), tambaqui (Colossoma macropomum), aruanã (Osteoglossum macropomum), pirapitinga (Piaratus brachypomum), entre outras espécies, que tinham desaparecido com a pesca predatória.

\section{OS CONFLITOS E A IMPLANTAÇÃO DO ACORDO DE PESCA}

A decisão acordada em 1974, de suspensão provisória por um período de seis meses, do uso das malhadeiras nos lagos da comunidade, provoca uma reação positiva nos anseios da comunidade, pois em pouco tempo ocorre um crescimento significativo dos estoques dos recursos pesqueiros nos logos e igarapés da comunidade. É justamente, neste contexto, que os moradores per- 
cebem nesta ação política a alternativa possível no processo de conservação e manejo dos recursos presentes em seu território pesqueiro. A partir de então, passaram a tomar decisões definitivas proibindo uso das malhadeiras e avançando em direção à consolidação de normas e regras de uso do território e, à discussão sobre a necessidade de firmar um acordo de pesca para a Ilha.

Figura 6 - O pirarucu é um importante nutriente da alimentação local e alvo da gestão dos recursos lacustres local.

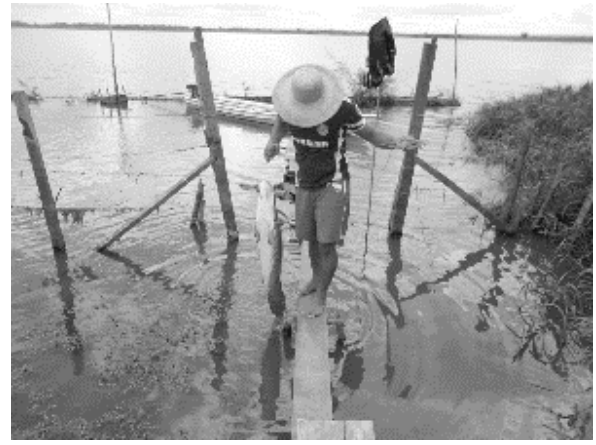

Fonte: Roberth Rodrigues Ferreira (2017).

Contudo, a afirmação da gestão do recurso, nos espaços de usufruto da comunidade, não ocorreu pacificamente. Não foram poucas as discordâncias de ideias, posições políticas e de interesses intra e extragrupais, gerando situações de conflitos entre os ilhéus e comunidades circunvizinhas. Na tentativa de manter os estoques pesqueiros e proibir a entrada de pescadores de outras localidades nos territórios manejados pelos pescadores da Ilha, os comunitários dão mais um passo. Orientados por um ex-morador e assessorado por um advogado, ambos residentes na cidade de Santarém - após muitos debates internos em 1983, elaboram um documento que só entra em vigor no ano de 1985, após ser homologado pela Comarca de Santarém, firmando definitivamente o acordo de pesca na comunidade.

Vale ressaltar que, antes de firmar este acordo de pesca, a comunidade inconformada com as sucessivas invasões de seus territórios de extração do pescado reage por meio de diversas iniciativas, envolvendo-se em atos de violência ou de decisão coletiva, redigindo documentos, seguidos de abaixo-assinados, buscando controle e disciplinamento do território.

"Nós abaixo assinados, proprietários de terras, usuários e moradores da Ilha de São Miguel, município de Santarém - Pará, contrariado com as constantes invasões provocadas por partes de pessoas inescrupulosas que além de utilizarem-se de nossas propriedades sem autorização, exploram-nas no ramo de pescarias utilizando utensílios destruidores e em época inadequadas, depredando e banindo nossas reservas (Acordo de Pesca 1985, s/p, cedido pela associação dos moradores da Ilha de São Miguel)"

Vê-se, no documento supracitado, uma reação coletiva na busca de impedir práticas que "violentam" e descumprem as formas de apropriação, controle e uso do território de exploração do pescado da comunidade por pescadores externos. Nesse entendimento, são formas legítimas que manifestam necessidades locais de gestão dos recursos pesqueiro nos lagos. A redação do acordo e sua homologação pela justiça mostram a preocupação da coletividade da Ilha de São Miguel, em preservar as espécies de pescado naquele espaço, a partir da 
restrição tanto do uso dos territórios de pesca, das espécies capturadas no decorrer do ano, como também dos apetrechos de pesca.

Figura 7 - O controle e uso do território para exploração do pescado da comunidade são formas legítimas que manifestam necessidades locais de gestão dos recursos pesqueiro nos lagos.

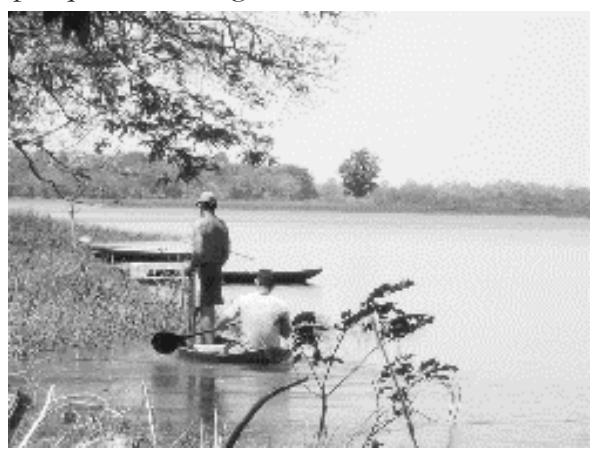

Fonte: Roberth Rodrigues Ferreira (2017).

Vê-se nesse documento, a ação de controle do território dos pescadores instituído através de cinco normas e regras elaboradas pelo grupo proibindo/restringindo apetrechos e a forma de realização dessa atividade na localidade, passando a ser proibido o trabalho da pesca exclusivamente para comercialização. Depois de efetivado o Acordo de Pesca para os lagos da Ilha de São Miguel, a partir de 2008 o Plano de Utilização (PU) dos recursos naturais os ilhéus, tornado legal pelo Instituto Nacional de Colonização e Reforma Agrária (INCRA), restringe a pesca e os recursos bióticos dos lagos apenas ao uso, acesso e usufrutos dos mesmos aos moradores daquele território, como enfatiza o capítulo IV - Intervenções agroextrativista / pesca no artigo 23 do PU: "fica proibido o uso de malhadeiras e espinhéis em toda área pertencente a comunidade de Ilha de São Miguel, sendo a pesca nessas áreas restrita apenas aos moradores da mesma. (2010, p. 14)", dialogando expressivamente com o Acordo de Pesca local:

"Visando a preservação das espécies de peixes que muito servem para manter nossas famílias [...] decidimos em reunião realizada no dia 24. 08. 85, conforme o acordo vigente desde 1983, manter para todos os lagos, baixas e outros locais de pescarias situado dentro da nossa localidade, o seguinte: Proibir em caráter permanente o uso de: 1 - Rede de pesca (malhadeira, bubuias, etc...), rede de arrasto, bombas e lanternas de carbureto; 2 - Espinhel em baixo de árvores frutíferas próprias para alimentação dos peixes; 3 - Pesca de pirarucu no período de 01 de outubro a 31 de março, conforme a Lei Federal; 4 - Tarrafa no Lago denominado "LAGUINHO", durante o período em que haja acesso para os peixes aos demais lagos, e 5 - Pesca com finalidade única e exclusiva para vender (ACORDO DE PESCA, 1985, s/p, cedido pela associação dos moradores da Ilha de São Miguel)".

Percebe-se como o Acordo de Pesca é um relevante instrumento de normatização dos recursos pesqueiros e sua consequente gestão.

\section{AS ESTRATÉGIAS DE CONSOLIDA- ÇÃO DO ACORDO: A GESTÃO DOS RECURSOS EM PRÁTICA}

Mesmo com a elaboração e construção do acordo de pesca local, as "invasões 
dos lagos" continuam acontecendo, obrigando ao grupo criar estratégias para legitimação de suas decisões. A primeira atitude de legitimar o território pesqueiro da comunidade ocorre com encaminhamento de cópias do acordo de pesca da Ilha às comunidades circunvizinhas, com o intuito de tornar o uso de seus territórios exclusivos e que as regras e normas estabelecidas no acordo de pesca fossem reconhecidas e respeitadas pelas demais comunidades.

Outra estratégia de manter o controle do pescado ocorre com as fiscalizações constantes nos lagos, procurando impedir a entrada de outros pescadores no espaço da Ilha. Essa ação é realizada por grupos de pescadores que se deslocam todas as noites de suas casas para as áreas de pescas na busca de manter o controle territorial da pesca.

"A gente fiscaliza essa área aqui durante a noite. A equipe de doze, quinze, vinte pessoas faz isso daí toda noite das seis as seis da manhã pra poder manter o trabalho nosso aqui dentro da comunidade. A gente tem sete equipes e nessas sete equipes faz essa rondagem aqui. Toda noite tem gente dentro do lago. (Entrevistado 05 e ex-presidente da Associação dos Nativos e Moradores da Ilha de São Miguel)".

Segundo os moradores, a prática de fiscalização dos lagos como ação política que restringiu definitivamente o uso dos recursos pesqueiro da Ilha conseguiu impedir entrada de pescadores de outras localidades nos lagos da Ilha mantendo o estoque pesqueiro constante, e isto põe em relevo a busca de afirmação da territorialidade dos ribeirinhos locais.

Contudo, mesmo havendo uma gestão dos recursos na comunidade, o grupo foi informado sobre a importância da criação de uma associação comunitária para a localidade pela necessidade de representação do grupo diante dos órgãos públicos e demais entidades, bem como criar uma organização fortalecendo a luta pela defesa do território dos pescadores. Com base nessa informação, a coletividade toma consciência da importância desta ação política e resolve, no ano de 1989 criar a associação comunitária na Ilha, definida como ANMISM, tendo como objetivo criar e manter a organização política da comunidade, bem como regular as atividades de conservação e manejo dos recursos pesqueiros nos igarapés e lagos.

"[...] prosseguiu Miguel, dizendo que embora há muito tempo residindo em Santarém, era natural de São Miguel, e que, por isso, estava voltando ali mais uma vez, para dar continuidade ao processo de organização da Sociedade local, iniciado com o encontro realizado no ano de 1983, do qual nasceu o ACORDO firmado por pessoas oriundas ou moradores da ilha, cujo acordo disciplinou a "pesca" nos lagos encravados na localidade, visando a preservação das espécies, que garantisse a alimentação dos ali residentes, representados pelas gerações de hoje e do futuro, ameaçada pela atividade pesqueira desordenada praticada pelos pescadores locais, e muito mais ameaçadas pela pesca agressiva e depredadora de pescadores das comunidades circunvizinhas, porque executada com 
objetivos unicamente comerciais (Ata de fundação da ANMISM 1989, cedida pela associação da comunitária)".

Esta fala de um ex-comunitário, retirada da ata da reunião realizada em 1989, é um marco na criação da associação comunitária da Ilha servindo de base para prosseguimento da gestão dos recursos nesse espaço. $\mathrm{O}$ grupo, neste contexto, toma consciência de que só por meio da associação, os comunitários teriam maior participação nas tomadas de decisão políticas dos assuntos relacionados aos interesses das famílias, uma vez que as reuniões/assembleias passam a ser realizadas mensamente e as tomadas de decisões são feitas por meio de votação dos associados. A associação passa a criar novas estratégias de gestão e de organização não somente do recurso pesqueiro, mas dos demais espaços da comunidade propondo normas e regras a todos usuários.

"É a associação que manda aqui dentro da comunidade, organiza tudo pra nós, tanto faz na parte do trabalho de limpeza de igarapé, faz trabalho também com o lixo na própria comunidade, faz trabalho nos igarapés ou pelas estradas, limpa estradas, limpa o colégio, campo de futebol, faz mutirão, a igreja faz mutirão pra limpar também (Entrevistado 01)".

A fala do entrevistado mostra a função que a ANMISM possui para a gestão do espaço da Ilha, criada para fortalecer a racionalidade do uso do recurso da pesca; ela assume também o papel de organização social para a coletivida- de, realizando ações coletivas, buscando melhor condições de vida para o grupo. Ademais, as ações determinadas nas reuniões e realizadas no espaço da comunidade têm respaldo e a participação dos associados.

As realizações das atividades designadas nas reuniões da associação são de responsabilidade dos associados; eles precisam participar de todo e qualquer movimento da associação que acontece na comunidade para poder usufruir de seus benefícios enquanto associados.

"O cara tem que tá quite na limpeza de estrada, quite na reunião, não pode falhar na reunião, tem que tá na vigilância do lago em dia, se falhar uma... ele tá fora do padrão" (Entrevistado 05 e ex-presidente da ANMISM).

$\mathrm{Na}$ fala do entrevistado, evidenciam-se os compromissos que cada associado da ANMISM possui para poder ter direito de usufruir de todos os benefícios possíveis que a entidade o ampara, que vão desde pescar nos lagos da comunidade até conseguir investimento financeiro - através de empréstimos bancários - para suprir uma necessidade que este venha a passar. Uma das principais ações tomadas pela associação ocorreu no ano de 1997 quando assumiu o controle de compra e venda do pescado no espaço da Ilha com a finalidade de garantir que nenhum dos associados descumprisse a regra que estipulava as espécies e o tamanho dos peixes que deveriam ser vendidos. Soma-se a isso, como garantia de autonomia financeira, a associação cobra uma 
taxa mensal para custear as despesas com deslocamento da diretoria para resolver pendências na cidade de Santarém, e com limpezas de espaços e locais na comunidade. A partir do momento em que os comunitários começaram a vender o pescado para a ANMISM, esta obteve o controle de produção anual do pirarucu principal peixe comercializado pelos associados da comunidade - e, por conseguinte, começou a pensar em estratégia para que este peixe não se exaurisse dos lagos da comunidade.

A entidade adota como estratégia o manejo do pirarucu com o intuito de controlar a comercialização dessa espécie e de garantir o equilíbrio da quantidade de pescado nos lagos da comunidade. Além da venda da produção das pescarias para a associação isso está ligado a outras medidas de caráter racional para a localidade, haja vista que as pescarias começaram a ser reguladas pela própria entidade. As pescarias passaram a ser realizada com horário fixo durante o dia - das seis horas às dezoito. Outra medida da associação é a contagem dos espécimes existentes nos lagos por equipes de monitoramento. Essa equipe é formada por um pequeno grupo de pescadores experientes, os quais passaram uma capacitação na Reserva de Desenvolvimento Sustentável de Mamirauá, no estado do Amazonas. A capacitação destes permitiu à associação manter controle tanto dos espécimes capturados como do número de matrizes que restam para reproduzir nos lagos da comunidade durante o ano.
Figura 8 - Processo de retirada das escamas do pirarucu.

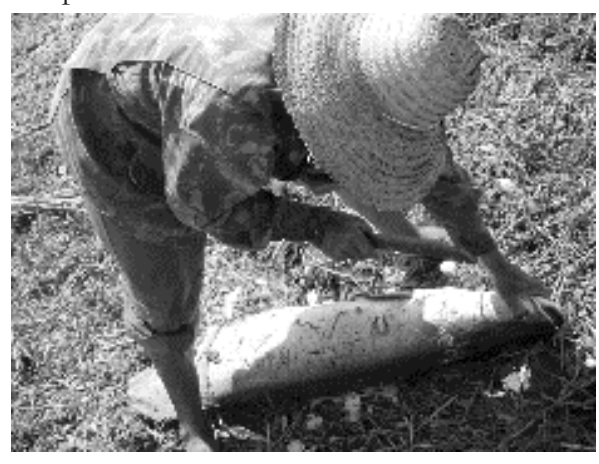

Fonte: Roberth Rodrigues Ferreira (2017).

Anualmente a contagem das matrizes de pirarucu nos seus territórios de extração (nos lagos, principalmente) é realizada antes do início das pescarias. Tal medida se faz necessária porque assim é possível averiguar a quantidade aproximada dos estoques da espécie e estimar quantos espécimes podem ser capturados no período destinado à atividade da pesca sem prejuízos para os próximos anos. Igualmente, nova contagem das matrizes de pirarucu é realizada no final de cada safra de pescaria. Esta medida é necessária porque só assim os pescadores podem levantar dados da quantidade de espécies presentes nos seus territórios para controle e manejo dos estoques nos anos seguintes.

Toda produção do pescado destinado à comercialização é controlada pela associação. Esta tem transporte próprio (barco) e faz o translado - comunidade Ilha de São Miguel/cidade de Santarém de toda produção semanalmente para comercialização do pescado. $\mathrm{O}$ barco é equipado com caixa térmica e fica à espera dos trabalhadores da pesca quando retornam de seu labor. Es- 
tes entregam toda produção ao encarregado do barco que mantém o peixe durante alguns dias fresco-gelado até o dia da comercialização na cidade de Santarém. Vale ressaltar que este barco não tem esta única finalidade, pois a entidade utiliza também para outras funções de interesse da coletividade.

Figura 9 - Toda produção do pescado destinado à comercialização é controlada pela associação.

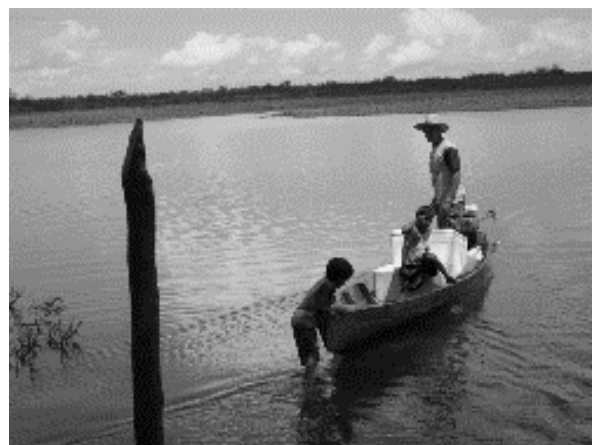

Fonte: Roberth Rodrigues Ferreira (2017).

Controlar todo o processo de produção do pescado na Ilha, torna-se importante medida política do grupo, uma vez que o peixe constitui um recurso fundamental para geração de renda e dieta alimentar das famílias. De posse destes dados, o grupo pode efetivamente realizar manejo do pirarucu, e aqui está a "fórmula de gestão" que os moradores da Ilha encontraram para concretizar a gestão do recurso de uso comum em favor da conservação do estoque de pescado e equilíbrio do gênero de vida local. Entretanto, em situações em que os trabalhadores da pesca percebam diminuição dos estoques pesqueiros nos lagos, agem rapidamente buscando soluções para evitar e dissipar possíveis ameaças à reprodução da vida do grupo no lugar. Ainda, todo este processo analisado é resultante da organização política do grupo. O "sucesso" ou "fracasso" de suas ações são determinados por reuniões e assembleias conduzidas pela associação de moradores da Ilha. As reuniões acontecem no primeiro sábado de cada mês para discutir e deliberar sobre assuntos ocorridos durante o intervalo de cada reunião e planejar ações para o mês vigente.

Nessas reuniões, as decisões tomadas são provenientes de votação por parte da assembleia presente. É neste momento que os associados expressam suas opiniões e dúvidas, acontecendo, portanto, comunicação entre o grupo, capaz de produzir efetivamente estratégias de gestão do espaço da Ilha, determinando formas de uso e controle dos recursos disponíveis, e isso tem garantido evolução e estabilidade do gênero de vida, gerando valores e sucessão deste grupo de camponeses ribeirinhos das várzeas do Rio Amazonas.

Assim, entende-se que gestão dos recursos pesqueiros por meio da construção coletiva do acordo de pesca, o qual impõe regras e normas que restringe uso do território de extração do pescado, foi o principal elemento indutor no processo de restauração do estoque pesqueiro na comunidade Ilha de São Miguel.

\section{CONSIDERAÇÕES FINAIS}

Os ilhéus são associados à Colônia de Pescadores Z-20 do município de 
Santarém. Esta afiliação é importante no sentido de contribuir à efetivação da gestão da pesca na localidade, pois a Z-20 tem conhecimento do acordo de pesca local e o legitima. Vale frisar que é de interesse da colônia a preservação e conservação dos estoques pesqueiros na área de abrangência de sua atuação política e social. A colônia participa, quando convocada, das reuniões locais para esclarecer questões referentes às práticas da pesca e ajudar a resolver os conflitos de pesca existentes entre os moradores da Ilha e as comunidades circunvizinhas. Portanto, a operacionalização do acordo de pesca na comunidade é realizada pelos pescadores locais e a articulação política com a Colônia de Pescadores Z-20, que os representa e legitima suas ações.

Atualmente, os comunitários vêm passando por limitações para manter a gestão da pesca na comunidade, pois mesmo operacionalizando um conjunto de ações - visando a manutenção do estoque do pescado - ocorrem invasões nos lagos da comunidade por pescadores de fora causando conflitos entre os pescadores da Ilha e os das outras comunidades. A dimensão física dos lagos e a distância deles em relação aos pontos de moradia dos pescadores são um fator limitante à efetivação da vigilância comunitária dos lagos. Daí a ocorrência das invasões dos lagos ser sempre uma ameaça aos estoques pesqueiros que os ilhéus consideram de usufruto comunitário.
Figura 10 - A invasão dos lagos comunitários é uma ameaça frequente aos estoques pesqueiros locais

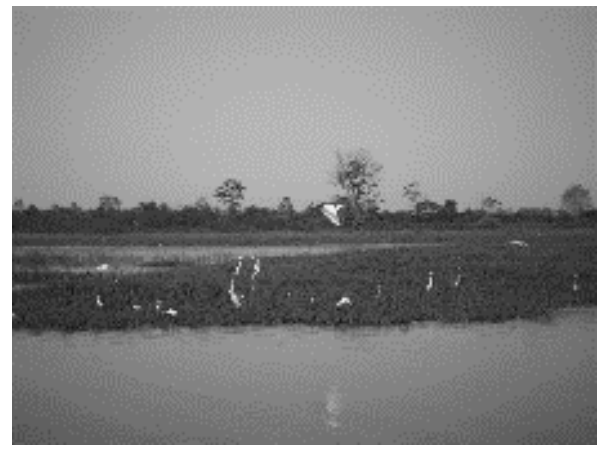

Fonte: Roberth Rodrigues Ferreira (2017).

As transformações ocorridas nas últimas décadas no âmbito da pesca artesanal nas águas interiores obrigam-nos a compreender essa atividade produtiva numa perspectiva sociobiodiversa, uma vez que instabilidades nos recursos bióticos afetam estruturalmente a qualidade de vida das comunidades que vivem da pesca artesanal. Como aponta Furtado (1997) o falto de políticas efetivas aliadas à fragilidade das organizações políticas dos pescadores ocasiona a invisibilidade das reivindicações e anseios dos pescadores enquanto categoria social, em busca de reconhecimento social (Silva 2012, Silva 2016). As ações desenvolvidas pelos comunitários da Ilha de São Miguel foram fundamentais para a permanência da população nesse espaço, pois a construção, implantação e consolidação do acordo de pesca trouxeram melhores condições de vida às famílias da localidade a partir da reestabelecimento das espécies de peixe nos lagos da comunidade. Pontuamos que foram fundamentais as considerações efetuadas pelos pareceristas desse periódico no sentido de 
contribuir na construção final do texto escrito ora aqui apresentado.

A conscientização quanto ao uso dos recursos pesqueiros nos lagos e igarapés da localidade fizeram com que os comunitários construíssem e instituíssem regras para uso e usufruto dos recursos pesqueiros na Ilha. Não obstante, no início da implementação das políticas de controle de extração do pescado, houve descontentamentos de alguns moradores locais e circunvizinhos com descumprimento das regras instituídas, forçando os moradores da Ilha cunhar estratégias para controle absoluto do território extrativo.

Estas ações políticas do grupo sobre o uso dos recursos pesqueiros nos lagos trouxeram resultados positivos, fazendo os moradores lutar para legitimar o acordo, uma vez que só desta maneira seriam respeitados os seus direitos de uso exclusivo. Desta forma as ações exercidas na Ilha de São Miguel com a criação do acordo de pesca evidenciam uma alternativa promissora para uma gestão da pesca por meio de uma prática sustentável, evidenciada no uso racional dos recursos pesqueiros, além de assegurar a qualidade de vida a todos os moradores da ilha.

\section{NOTAS}

${ }^{1}$ Graduado em Geografia pela Universidade Federal do Oeste do Pará (ICED) e Mestrando no Programa de Pós-Graduação em Sociedade, Ambiente e Qualidade de Vida - CFI / Universidade Federal do Oeste do Pará. Bolsista da CAPES.

${ }^{2}$ Mestre e Doutor em Sociologia pela Universidade Federal da Paraíba. Professor do Quadro Permanente do Programa de Pós-Graduação em Sociedade, Ambiente e Qualidade de Vida e do Programa de Pós-Graduação em Ciências da Sociedade pela Universidade Federal do Oeste do Pará.

${ }^{3}$ Ao longo do texto será usada a sigla ANMISM.

\section{REFERÊNCIAS}

ANMISM. 1985. Associação dos Nativos e Moradores da Ilha de São Miguel. Acordo de Pesca da Comunidade Ilha de São Miguel. Santarém - PA.

1989. Ata de reunião da fundação da Associação dos Nativos e Moradores da Ilha de São Miguel-ANMISM. Santarém - PA.

Azevedo, C. R. Apel, M. 2004. Co-gestão: Um processo em construção na váržea amazônia. Manaus: ProVárzea/IBAMA.

Batista, V. da S. et al. 2004. Exploração e manejo dos recursos pesqueiros na Amazônia, in: A pesca e os recursos pesqueiros na Amazônia brasileira, pp. 63-151. Organizado por M. L. Ruffino. Provárzea/IBAMA

Berkes, F. et al. 2006 Gestão da pesca de pequena escala: diretrizes e métodos alternativos. Rio Grande/RS: EdFURG.

Bosi, E. 2003. O tempo vivo da memória: ensaios de psicologia social. São Paulo: Ateliê Editorial.

Cerdeira, R. G. P. 2009. Acordo de Pesca como instrumento de Gestão Participativa na Amazônia. Dissertação de Mestrado (Mestrado em Direito Ambiental). Universidade do Estado do Amazonas, Brasil.

Diegues, A. C. S. 1983. Pescadores, camponeses e trabalhadores do mar. São Paulo: Ática.

Furtado, L. G. 1997. Problemas ambientais e pesca tradicional na qualidade de vida na Amazônia, in Amazônia, desenvolvimento, sociodiversidade e qualidade 
de vida, pp. 146-165. Organizado por L. G. Furtado. Belém: EDUFPA.

Halbwachs, M. 2006. A memória coletiva. São Paulo: Centauro.

Hardin, G. 1968. The Tragedy of the Commons. Science 162(3859):1243-1248.

Hartmann, W. D. 2001. Conflitos de pesca em águas interiores da Amazônia e tentativas para sua solução, in Espaços e recursos naturais de uso comum, pp. 125-138. Organizado A. C. Diegues, A. de C. Moreira. São Paulo: Nupaub - USP.

INCRA, Instituto Nacional de Colonização e Reforma Agrária; IPAM, Instituto de Pesquisa Ambiental na Amazônia. 2010. Projeto Básico de Desenvolvimento Sustentável do Assentamento Agroextrativista Aritapera. Santarém.

Lathrap, D. W. 1968 The hunting economies of the tropical forest zone of South America: an attempt at historical perspective, in Man the hunter. Organizado por R. Lee, I. DeVore Aldine, Chicago.

Lima, L. C. 2014. Verificação dos Acordos de Pesca na região do Tapará, Santarém, Pará. Monografia (Aperfeiçoamento/Especialização em Sociedade, Meio Ambiente e Desenvolvimento Sustentável na Amazonia) - Universidade Federal do Oeste do Pará.

Maybury-Lewis, B. 1997. Terra e água: identidade camponesa como referência de organização política entre os ribeirinhos do Rio Solimões, in Amazônia, desenvolvimento e qualidade de vida, pp. 31-69. Organizado por L. G. Furtado.Belém; UFPA / NUMA.

Mcgrath, D. G. et al. 1993. Manejo Comunitário da pesca nos lagos de várzea do Baixo Amazonas, in: Povos das Águas, realidade e perspectiva na Amazônia, pp. 213-219 . Organizado por L. G. Furtado, W. Leitão, A. F. Mello. Coleção Eduardo Galvão, PR/ MCT/CNPq, MPEG, Belém.
Meggers, B. J. 1971. Amazonia: man and culture in a counterfeit paradise. Aldine / Atherton: Chicago.

Mello, A. F. 1993. Pescadores da Indústria: o complexo de Icoracy, in: Povos das Águas, realidade e perspectiva na Amazônia, pp. 8399. Organizado L. G. Furtado, W. Leitão, A. F. Melo. Coleção Eduardo Galvão, PR/ MCT/CNPq, MPEG, Belém.

Ostrom, E. 2011. El gobierno de los bienes comunes: La evolución de las instituciones de acción colectiva. [trad. e rev. tec. Leticia Merino Perez]. 2. ed. México: FCE, UNAM, IIS.

Oviedo, A. F. P. Bursztyn, M. et al. 2015. Agora sob nova administração: acordos de pesca nas várzeas da Amazônia Brasileira. Revista Ambiente \& Sociedade 18(4):119-138. São Paulo

Ruffino, M. L. 2005. Gestão do uso dos recursos pesqueiros na Amazônia. Manaus: Provárzea/ IBAMA.

Santos, G. M. Santos, A. C. M. 2005. Sustentabilidade da pesca na Amazônia. Estudos Avançados [online] 19(54):165-182.

Smith, N. J. H. 1979. A pesca no rio Amazonas. Manaus: INPA.

Silva, R. E. Salgado, A. M. F. 2016. Gestão social das águas na FLONA e Reserva Extrativista do Tapajós-Arapiuns: estudo socioantropológico sobre os conflitos para demarcação de zonas de pesca e mobilização social para a gestão e preservação dos territórios de pesca comunitária. Relatório Final do Projeto de Iniciação Científica (PROPPIT / Universidade Federal do Oeste do Pará).

Silva, R. E. 2012. Guiados por mares e peixes: memória social, inovação tecnológica e o processo de fragmentação na pequena pesca mercantil em duas comunidades costeiras no Rio Grande do Norte. Tese de Doutorado, UFPB, Brasil.

2016. Imagem e pescadores costeiros: a visualidade como elemento 
articulador do reconhecimento de si e de afetos em contexto de pesquisa de campo numa sociedade costeira - o caso de Baía Formosa, Rio Grande do Norte, Brasil. Revista Vivência 47:89-110.

Veríssimo, J. 1970. A pesca na Amazônia. Belém: UFPA.

Ximenes, T. 2008. Capital social, redes sociais e inovações produtivas. Ambiente e sociedade. Campinas 11(2): 389-404.

Recebido em 10/06/2017

Aprovado em 02/08/2017 